\title{
From Psychological Intention Recognition Theories to Adaptive Theory of Mind for Robots: Computational Models
}

\author{
Francesca Bianco ${ }^{\dagger}$ \\ School of Computer Science and Electronic Engineering \\ \& Department of Psychology \\ University of Essex \\ United Kingdom \\ fb18599@essex.ac.uk
}

\author{
Dimitri Ognibene \\ School of Computer Science and Electronic Engineering \\ University of Essex \\ United Kingdom \\ Dimitri.ognibene@essex.ac.uk
}

\begin{abstract}
Progress in robots' application to everyday scenarios has increased the interest in human-robot interaction (HRI) research. However, robots' limited social skills are associated with decreased humans' positive attitude during HRI. Here, we put forward the idea of developing adaptive Theory of Mind (ToM) model-based systems for social robotics, able to deal with new situations and interact with different users in new tasks. Therefore, we grouped current research from developmental psychology debating the computational processes underlying ToM for HRI strategy development. Defining a model describing adaptive ToM processes may in fact aid the development of adaptive robotic architectures for more flexible and successful HRI. Finally, we hope with this report to both further promote the cross-talk between the fields of developmental psychology and robotics and inspire future investigations in this direction.
\end{abstract}

KEYWORDS: Theory of Mind; Intention Recognition; Belief Recognition; Action recognition; Prediction; User state

ACM Reference format:

Francesca Bianco and Dimitri Ognibene. 2020. From Psychological Intention Recognition Theories to Adaptive Theory of Mind for Robots: Computational Models. In HRI'20 Companion: Conference on ACM/IEEE International Conference on Human-Robot Interaction, March 23-26, 2020, Cambridge, UK. ACM, New York, NY, USA, 2 pages. https://doi.org/10.1145/3371382.3378364

\section{Introduction}

Together with the recent introduction of robots in increasing everyday scenarios, human-robot interaction (HRI) research has rapidly evolved and various types and forms of interactions are being investigated [1-3]. However, although research in robots' industrial application has been highly reported, that in areas requiring additional social interaction is still at initial stages [4]. Indeed, the growing interest of HRI has mainly focused on the tuning of specific parameters to increase humans' positive response to robots.

Permission to make digital or hard copies of part or all of this work for personal or classroom use is granted without fee provided that copies are not made or distributed for profit or commercial advantage and that copies bear this notice and the full citation on the first page. Copyrights for third-party components of this work must be honored. For all other uses, contact the Owner/Author(s).

HRI '20 Companion, March 23-26, 2020, Cambridge, United Kingdom

(C) 2020 Copyright is held by the owner/author(s).

ACM ISBN 978-1-4503-7057-8/20/03. https://doi.org/10.1145/3371382.3378364
An example is provided by [5] which reports an influence of the environment conditions on humans' perception of a "dancing robot" performance. Most of these systems, however, do not rely on model-based frameworks and overlook the way in which humans interact, preventing their adaptation to general situations. In fact, building robots as social agents, thus able to autonomously infer humans' intentions and beliefs and to adapt their behaviour both in various environments and when interacting with different people, remains one of the biggest challenges in robotics [6]. Previously [7, 8], we highlighted the need for a cross-talk between robotics and developmental psychology as a means to advance robots' social skills and improve HRI. Specifically, we suggested the integration of a human-inspired adaptive Theory of Mind (ToM) in the architectures for social robots to do so. In addition, four main functional advantages of equipping robots with an adaptive ToM with respect to current robotic architectures were identified, namely belief understanding and tracking, proactivity, active perception and learning (see [7] for further details). However, human ToM is characterised differently in the literature and it is yet to be fully defined [8]. To advance this debate, we thus identified a few important questions to be answered which would aid the integration of an adaptive ToM model in social robot architectures. Among these, is the understanding of which computational processes may underlie human ToM development. In the next section, a brief description of the main accounts suggested as precursors of ToM will be provided, together with tables summarising current psychology experiments addressing this topic. Finally, their importance for HRI will be highlighted to further support this cross-talk between different research fields[9].

\section{Computational Models Underlying ToM}

In psychology, three main accounts are utilised to describe the human ability to understand intentions from observed actions, i.e. the association, simulation and teleological theories. The actioneffect association theory is the simplest one, which states that goals are inferred by "simple associations between an observed action and the effects that one's actions have produced" [10]. The simulation theory is the next more complex one, according to which "actions are understood when the observer directly matches, or mirrors, the observed action onto their own motor system" [11]. The last teleological theory states that "the outcome of an action is seen as the goal, depending on whether it is judged to justify the action in the given situation according to the 
rationality principle" [10]. Here, we provide a summary table (see Table 1 below) of state-of-the-art experiments from the world of developmental psychology researching infants' ability to use the different accounts during development. We hope to also further promote a successful cross-talk between the fields of HRI and developmental psychology [9, 12, 13]. Indeed, current robots' architectures generally rely on association and simulation principles to enable robots to learn about the social world, enabling them to recognize and predict actions from observing other agents performing such actions $[12,13]$.

Table 1. Summary table of developmental psychology experiments describing infants' cognitive ability to predict goaldirected actions supported by different computational theories

\begin{tabular}{|c|c|c|c|}
\hline Study & Task & Findings & $\begin{array}{c}\text { Supported } \\
\text { Computational } \\
\text { Theory }\end{array}$ \\
\hline $\begin{array}{l}\text { Woodward, } \\
1998\end{array}$ & $\begin{array}{l}\text { Prediction of } \\
\text { grasping } \\
\text { action }\end{array}$ & $\begin{array}{l}\text { After seeing a hand repeatedly } \\
\text { grasping one of two objects, infants } \\
\text { anticipate that the same object would } \\
\text { be grasped again, even when the } \\
\text { spatial location of the objects are } \\
\text { rearranged }\end{array}$ & Association \\
\hline $\begin{array}{l}\text { Monroy } \\
\text { et a1., } \\
2017\end{array}$ & $\begin{array}{l}\text { Prediction of } \\
\text { action } \\
\text { sequence }\end{array}$ & $\begin{array}{l}\text { Observing actions, but not visual } \\
\text { events, influenced toddlers' action } \\
\text { choices when associated with an } \\
\text { effect. }\end{array}$ & Association \\
\hline $\begin{array}{l}\text { Southgate } \\
\text { et al., } \\
2009\end{array}$ & $\begin{array}{l}\text { Prediction of } \\
\text { grasping } \\
\text { action }\end{array}$ & $\begin{array}{l}\text { Infants display overlapping neural } \\
\text { activity during execution and } \\
\text { observation of actions, but this } \\
\text { activation, rather than being directly } \\
\text { induced by the visual input, is driven } \\
\text { by infants' understanding of a } \\
\text { forthcoming action. }\end{array}$ & Simulation \\
\hline $\begin{array}{l}\text { Skerry } \\
\text { et a1., } \\
2013\end{array}$ & $\begin{array}{c}\text { Prediction of } \\
\text { grasping } \\
\text { action }\end{array}$ & $\begin{array}{l}\text { Infants apply a general assumption of } \\
\text { efficient action as soon as they have } \\
\text { sufficient information (possibly } \\
\text { derived from their own action } \\
\text { experience) to identify an agent's goal } \\
\text { in a given instance }\end{array}$ & $\begin{array}{l}\text { Possibly } \\
\text { Simulation for } \\
\text { Teleological }\end{array}$ \\
\hline $\begin{array}{l}\text { Csibra } \\
\text { et al., } \\
2003\end{array}$ & $\begin{array}{l}\text { Goal } \\
\text { attribution to } \\
\text { uncompleted } \\
\text { action }\end{array}$ & $\begin{array}{l}\text { Infants use the principle of rational } \\
\text { action for the interpretation and } \\
\text { prediction of goal-directed actions, but } \\
\text { also for making productive inferences } \\
\text { about unseen aspects of their context }\end{array}$ & Teleological \\
\hline $\begin{array}{l}\text { Southgate } \\
\text { et al., } \\
2008\end{array}$ & $\begin{array}{c}\text { Prediction of } \\
\text { goal-directed } \\
\text { action }\end{array}$ & $\begin{array}{c}\text { Infants appear to extend goal } \\
\text { attribution even to biomechanically } \\
\text { impossible actions as long as they are } \\
\text { physically efficient }\end{array}$ & Teleological \\
\hline
\end{tabular}

Although several studies provided computational models of ToM based on the accounts above described [19, 20], we previously debated that such computational processes do not fully explain the way in which we are also able to infer abstract mental states (ToM components), such as intentions, desires and beliefs (see $[7,8]$ for more details on current robotic architectures for ToM). Similarly, we suggest that humans are able to access more complex concepts than those described by the previous accounts, which cannot be inferred through action observation. Likewise, robots' recognition of complex mental states and their understanding of the humans they interact with is limited when based on the mentioned theories. For example, although robots can recognize the action of displacing objects in a room, they do not understand the deeper mental state of the observed agent, e.g., desire to search for glasses. However, we proposed that these models may be important for and precursors of ToM. Different researchers have attempted to link one of these theories and ToM, contributing to the debate. Here, we illustrate some of these investigations in Table 2 below to both group such proposals, to the best of our knowledge, for the first time and inspire future studies in this direction. Specifically, we believe that defining whether such computational processes can cooperate to build a ToM or whether they are mutually exclusive is essential for characterising ToM and provide a truthful description of the underlying computational processes. This will in turn prove useful for the development of adaptive architectures for social robots.

Table 2. Summary of psychology experiments describing precursor computational models of human Theory of Mind ability

\begin{tabular}{|c|c|c|c|}
\hline Study & $\begin{array}{l}\text { Precursor of } \\
\text { Theory of } \\
\text { Mind }\end{array}$ & Proposal & Experiments \\
\hline $\begin{array}{l}\text { Keysers } \\
\text { \& Gazzola, } \\
2006\end{array}$ & $\begin{array}{l}\text { Simulation } \\
\text { as precursor of } \\
\text { Theory of } \\
\text { Mind }\end{array}$ & $\begin{array}{l}\text { Based on neural evidence: brain } \\
\text { areas associated with both } \\
\text { accounts represent simulation } \\
\text { (even though at different levels) }\end{array}$ & N/A \\
\hline $\begin{array}{l}\text { Gergely } \\
\text { \& Csibra, } \\
2003\end{array}$ & $\begin{array}{l}\text { Teleological } \\
\text { as precursor of } \\
\text { Theory of } \\
\text { Mind }\end{array}$ & $\begin{array}{l}\text { Continuum between teleological } \\
\text { constructs (i.e., action, goal-state } \\
\text { and situational constraints) and } \\
\text { mentalistic ones (i.e., intentions, } \\
\text { desires and beliefs), with the } \\
\text { latter supposing same } \\
\text { computations and constructs of } \\
\text { the former but representing more } \\
\text { sophisticated, abstract constructs }\end{array}$ & $\begin{array}{l}12 \text {-month-old infants had } \\
\text { to infer a goal state to } \\
\text { rationalize the incomplete } \\
\text { action, whose end state was } \\
\text { occluded from them, as an } \\
\text { efficient 'chasing' action }\end{array}$ \\
\hline $\begin{array}{l}\text { Baker } \\
\text { et al., } \\
2017\end{array}$ & $\begin{array}{l}\text { Teleological } \\
\text { as precursor of } \\
\text { Theory of } \\
\text { Mind }\end{array}$ & $\begin{array}{c}\text { Bayesian computational model } \\
\text { for ToM based on the } \\
\text { teleological principle: adults } \\
\text { were suggested to follow this } \\
\text { model to infer the mental states } \\
\text { behind an agent's behavior using } \\
\text { priors }\end{array}$ & $\begin{array}{l}\text { 'Food-trucks' scenario, } \\
\text { using animated two- } \\
\text { dimensional displays of an } \\
\text { agent navigating through } \\
\text { simple grid-worlds. } \\
\text { Observers had to infer } \\
\text { agents' mental states } \\
\text { according to their } \\
\text { trajectory }\end{array}$ \\
\hline $\begin{array}{l}\text { Hamlin } \\
\text { Et al., } \\
2013\end{array}$ & $\begin{array}{l}\text { Teleological } \\
\text { as precursor of } \\
\text { Theory of } \\
\text { Mind }\end{array}$ & $\begin{array}{l}\text { Bayesian computational model } \\
\text { for ToM based on the } \\
\text { teleological principle: infants } \\
\text { were suggested to follow this } \\
\text { model to infer the mental states } \\
\text { behind an agent's behavior }\end{array}$ & $\begin{array}{l}\text { Evaluation of social actions } \\
\text { between agents (helping or } \\
\text { harming intentions of } \\
\text { agents during interaction) }\end{array}$ \\
\hline
\end{tabular}

\section{Conclusion}

In this paper, we grouped some key findings in developmental psychology concerning current computational theories describing intention understanding from observed actions, which have also inspired the development of architectures for social robots. In addition, we summarised some current attempts in psychology to describe the human higher-level ToM ability for mental states inference and propose both psychology and robotics studies to continue in this direction. Specifically, we would like to further stress the importance of the cross-talk between the two research fields. Indeed, understanding how infants develop such social skills may be a resource for more adaptive and complex robotic systems, improving HRI and increasing the application of robots in additional social scenarios. 


\section{REFERENCES}

[1] A. Abubshait, and E. Wiese, "You Look Human, But Act Like a Machine: Agent Appearance and Behavior Modulate Different Aspects of Human-Robot Interaction," Front Psychol, vol. 8, pp. 1393, 2017.

[2] L. Sinnema, and M. Alimardani, "The Attitude of Elderly and Young Adults towards a Humanoid Robot as a Facilitator for Social Interaction. ," 2019

[3] Alessia Vignolo, Alessandra Sciutti, Francesco Rea, and J. Michael, "Spatiotemporal Coordination Supports a Sense of Commitment in HumanRobot Interaction," 2019.

[4] T. B. Sheridan, "Human-Robot Interaction: Status and Challenges," Human Factors, vol. 58, no. 4, pp. 525-532, 2016.

[5] Cecilia Roselli, Francesca Ciardo, and A. Wykowska, "Robots Improve Judgments on Self-generated Actions: An Intentional Binding Study."

[6] J. B. G.Z. Yang, P. E. Dupont, P. Fisher, L. Floridi, R. Full, et al, "The grand challenges of science robotics," Science Robotics, vol. 3, pp. eaar7650, 2018.

[7] F. Bianco, Ognibene, D., "Functional Advantages of an adaptive Theory of Mind for robotics: a review of current architectures."

[8] F. Bianco, Ognibene, D., "Transferring adaptive Theory of Mind to social robots: insights from developmental psychology."

[9] S. Lemaignan, and P. Dillenbourg, "Mutual Modelling in Robotics: Inspirations for the Next Steps," ACM/IEEE International Conference on Human-Robot Interaction, vol. 2015, pp. 303-310, 03/02, 2015.

[10] G. G. Csibra G, “'Obsessed with goals': Functions and mechanisms of teleological interpretation of actions in humans," acta psychol, vol. 124, no. 1, pp. 60-78, 2007.

[11] V. Southgate, M. H. Johnson, and G. Csibra, "Infants attribute goals even to biomechanically impossible actions," Cognition, vol. 107, no. 3, pp. 1059-69, Jun, 2008.
[12] A. Cangelosi, and M. Schlesinger, "From Babies to Robots: The Contribution of Developmental Robotics to Developmental Psychology," Child Development Perspectives, vol. 12, no. 3, pp. 183-188, 2018.

[13] Y. Demiris, and A. Dearden, "From motor babbling to hierarchical learning by imitation: a robot developmental pathway," Proceedings of the 5th International Workshop on Epigenetic Robotics, pp. 31-37, 2005.

[14] A. L. Woodward, "Infants selectively encode the goal object of an actor's reach," Cognition, vol. 69, no. 1, pp. 1-34, Nov, 1998.

[15] C. Monroy, S. Gerson, and S. Hunnius, "Infants' Motor Proficiency and Statistical Learning for Actions," Front Psychol, vol. 8, pp. 2174, 2017.

[16] V. Southgate, M. H. Johnson, T. Osborne, and G. Csibra, "Predictive moto activation during action observation in human infants," Biol Lett, vol. 5, no. 6 , pp. 769-72, Dec 23, 2009.

[17] A. E. Skerry, S. E. Carey, and E. S. Spelke, "First-person action experience reveals sensitivity to action efficiency in prereaching infants," Proceedings of the National Academy of Sciences, vol. 110, no. 46, pp. 18728-18733, 2013.

[18] G. Gergely, and G. Csibra, "Teleological reasoning in infancy: the nai;ve theory of rational action,” Trends Cogn Sci, vol. 7, no. 7, pp. 287-292, Jul, 2003

[19] L. Hiatt, A. Harrison, and J. Trafton, Accommodating Human Variability in Human-Robot Teams through Theory of Mind, 2011.

[20] A. F. T. Winfield, "Experiments in Artificial Theory of Mind: From Safety to Story-Telling," Frontiers in Robotics and AI, vol. 5, no. 75, 2018-June-26, 2018

[21] C. Keysers, and V. Gazzola, "Integrating simulation and theory of mind: From self to social cognition," Trends in Cognitive Sciences, vol. 11, no. 5, pp. 194-196, 2007.

[22] C. L. Baker, J. Jara-Ettinger, R. Saxe, and J. B. Tenenbaum, "Rational quantitative attribution of beliefs, desires and percepts in human mentalizing," Nature Human Behaviour, vol. 1, no. 4, pp. 0064, 2017.

[23] J. Hamlin, T. Ullman, J. Tenenbaum, N. Goodman, and C. Baker, "The mentalistic basis of core social cognition: experiments in preverbal infants and a computational model," Dev Sci, vol. 16, no. 2, pp. 209-226, Mar, 2013. 